Article

\title{
Modular Multilevel Converter for Photovoltaic Application with High Energy Yield under Uneven Irradiance
}

\author{
Anirudh Budnar Acharya ${ }^{1, * \mathbb{C}}$, Dezso Sera ${ }^{2} \mathbb{D}$, Remus Teodorescu ${ }^{1}\left[\right.$ and Lars Einar Norum $^{3}$ \\ 1 Department of Energy Technology, Aalborg University, 9220 Aalborg, Denmark; ret@et.aau.dk \\ 2 School of Electrical Engineering and Robotics, Queensland University of Technology, \\ Brisbane, QLD 4000, Australia; dezso.sera@qut.edu.au \\ 3 Department of Electric Power Engineering, Norwegian University of Science and Technology, \\ 7491 Trondheim, Norway; norum@ntnu.no \\ * Correspondence: abac@et.aau.dk
}

Received: 3 April 2020; Accepted: 18 May 2020; Published: 21 May 2020

\begin{abstract}
The direct integration of Photovoltaic (PV) to the three-phase Modular Multilevel Converter (MMC) without $d c-d c$ converters results in high-efficiency PV power plant with increased energy yield. The arm power control method for the MMC further improves the extraction of available power under uneven irradiance across different phases of the MMC. However, the uneven irradiance between the sub-modules results in residual voltage that results in harmonics and unbalance components. In this paper, the effect of uneven irradiance across the sub-module of the MMC is investigated with arm power control method. A modified balancing algorithm for the arm power control of the MMC is proposed which enables balanced power to be injected into ac grid despite uneven irradiance across the sub-modules in the MMC. The modified balancing algorithm enables to keep the unbalance in the phase currents below $10 \%$ and the Total Harmonic Distortion (THD) is confined as per IEEE 519 standard.
\end{abstract}

Keywords: modular multilevel converter; photovoltaic power system; grid integration; control system; distributed renewable energy source

\section{Introduction}

The aim of decreasing the emission of greenhouse gas to minimize the impact on the environment has given a tremendous push to power plants based on renewable energy sources. Solar power is abundantly available and many countries have pledged to use $100 \%$ renewable energy by 2050 [1]. The large share of energy consumption from renewable sources will be contributed by solar power in the near future. As the extraction of solar power is highly weather-dependent, efficient power converters are necessary that can harvest the available power at all weather conditions.

Modular PV power plants are preferred in locations where energy yield is impacted due to varying weather conditions. Furthermore, modular PV power plants are preferred for commercial installation where partial shading of the panel is a concern. The modular power converters decrease the effects of PV panel mismatch as compared to central power converters where the PV panels are connected to form an array. The modularity of such converters can be a panel, string, or array level. However, in most of the cases the modularity is achieved at the cost of additional $d c-d c$ converters [2].

The PV power plant using Cascaded H-Bridge (CHB) converter is studied in [3,4], it operates at high efficiency and increases energy yield due to increase in number of Maximum Power Point Tracking (MPPT). The Modular Multilevel Converter (MMC) proposed in [5] increases the number of MPPT for the same number of switches compared to the CHB converter. The MMC topology, its 
variants, and applications are discussed in [6,7]. In [3,8,9], MMC is proposed as an inverter for PV plant. The detailed discussion on topology and control methods for the MMC are presented in [10]. The Figure 1a shows a three-phase double star MMC with Half-Bridge (HB) sub-modules. Each phase of the MMC can be divided into sub-units referred to as upper and lower arm, respectively. Each arm of the MMC has series-connected power electronic blocks referred to as "sub-modules" and an inductor referred to as "arm inductor". The sub-modules can be identical or a combination of different power converter topologies [11]. Typically used sub-modules are half-bridge or full-bridge converters.

Three distinct variants of the topology for connecting the PV panels to the sub-modules are shown in Figure 1b-d. In [12,13], the PV panels are directly connected to the sub-module of the MMC as shown in Figure 1b. The overall efficiency of the PV plant is considerably high as the MMC efficiency is in the range of $99 \%$ [14]. Such a system is comparable to the central PV power plant with the additional benefit of an increased number of independent MPPT algorithms, which in this case is equal to the number of sub-modules. This results in higher energy yield and better efficiency than the central PV power plant. In [15], the authors show that the Levelized Cost of Energy (LCOE) for the MMC-based PV plant can be brought lower than that of the central PV plant. The PV panels connected to the sub-modules using the $d c-d c$ converters is shown in Figure $1 c, d$. The use of a $d c-d c$ converter allows the decoupling of the PV control and the MMC control. The advantage is that the sub-module capacitor voltages across the MMC are equal; therefore, no modification is necessary in the MMC control. However, in this configuration the overall efficiency is lower compared to PV plant without $d c-d c$ converters. In cases where the isolated converters are used, the $d c$-link voltage can be scaled to Medium Voltage (MV) facilitating direct connection of the MMC PV plant to the distribution grid. Thereby, avoiding the need for a step-up transformer typically used for connection to the MV grid.

In [16], the control method for the MMC uses individual Pulse Width Modulators (PWM) for each of the sub-modules. In [17], the method presented in [16] is further extended to control the MMC with the energy sources connected to the sub-modules. The energy in each of the sub-module is locally controlled, which effectively provides the possibility of distributing the control between the main and local controllers. It uses phase-shifted PWM and additional sub-modules are necessary as energy buffers to avoid: (1) large variation of capacitor voltage in the sub-module with an energy source and (2) to avoid very high switching frequency of the sub-module. In $[18,19]$ the non-carrier based approach is used for controlling the MMC when the energy sources are connected to the sub-modules. The non-carrier based control method relies on calculating the fundamental positive and negative sequence circulating current references required to balance the energy between the upper and lower arms of the MMC. In [12], a cost function is presented to optimize the calculation of fundamental circulating current references for extracting the maximum power from the PV and injection of balanced power to the grid. Calculating weights for the cost function is not straight forward and is usually obtained from trial-and-error or extensive simulation cases. In [13], arm power control of MMC is presented, the control system is distributed such that each arm of the MMC is controlled independently. This method also avoids the mathematical computation of the fundamental circulating current references.

Using arm power control the MMC is controlled such that maximum power is extracted from the PV panels and a balanced power is injected to the $a c$ grid. The sum of sub-module capacitor voltages in an arm of the MMC is allowed to be different across the upper and lower arms of the MMC. However, within the arm of the MMC, all capacitor voltages are maintained to be equal. This is achieved with the help of sorting and tracking algorithm. The variation of the irradiance is assumed at arm-level for the three-phase MMC leading to six independent MPPT. Such an assumption is viable in large power plants were the effects of shading is minimal. In the case of residential and commercial PV plants, the consequence of shading between the sub-modules cannot be neglected. The shading of PV panels will result in a decrease of power extracted as the MMC is only capable of MPPT at arm-level. This will reduce the yield ratio and LCOE compared to the module-level power converters. 
The MMC with arm power control can enable MPPT at the sub-module level. This is achieved by providing individual sub-module capacitor voltage references obtained from the MPPT algorithm. As a result, the sub-module capacitor voltages within the arm of the MMC will not be equal to its average value. Therefore, the voltage inserted by each arm of the MMC will not be equal. As the output voltage in a phase of the MMC is the difference of the upper and the lower arm voltages, the unequal arm voltages will result in a residual voltage at the output terminal. A high deviation in the magnitude of the sub-module capacitor voltages in the arm of the MMC might result in higher residual voltage. This will result in undesired current harmonics and unbalance current components.

In this paper, the effect of unequal sub-module capacitor voltages in the arm of the MMC using arm power control is investigated. A modified sorting and balancing algorithm is proposed that allows the MMC-based PV plant with arm power control to track the MPPT at the sub-module level and inject balanced power to the $a c$ grid. The effect of phase current THD is analyzed in the case of uneven irradiance on the sub-modules. The modified sorting and tracking algorithm mitigates the residual voltage between the converter and grid voltages thereby reducing the THD in the phase currents. As a consequence of lower residual voltage the unbalance in the phase current is mitigated. The modified algorithm ensures balanced power injection to the $a c$ grid despite extreme unbalance in power generation. The proposed solution makes the arm power control for the MMC suitable for PV applications which are prone to uneven irradiance.

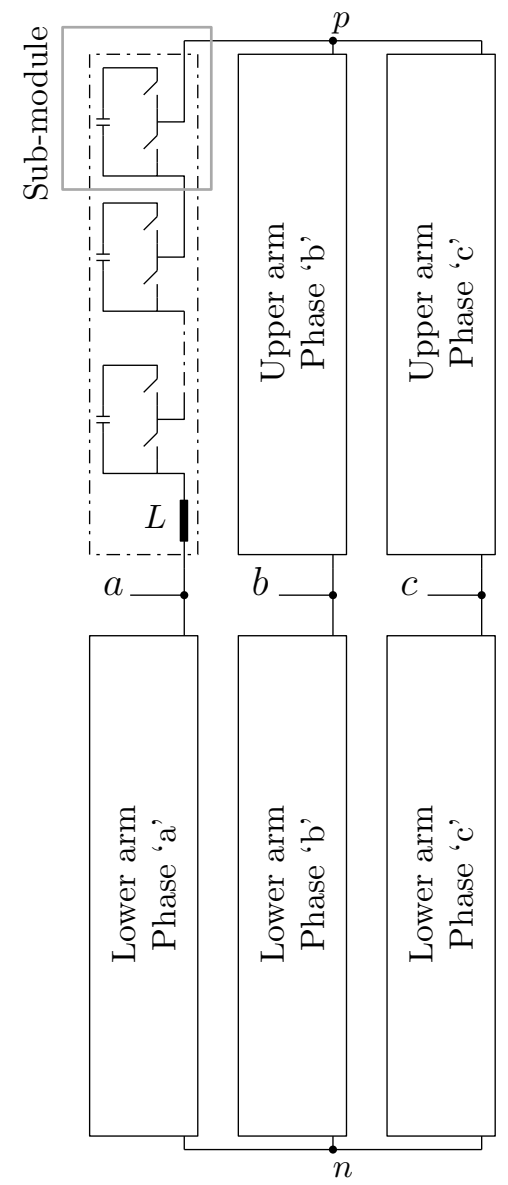

(a)

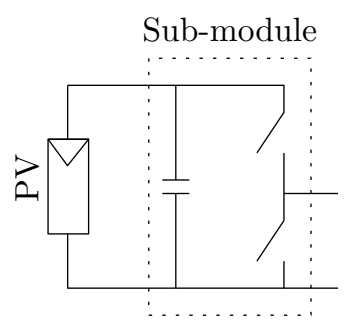

(b)

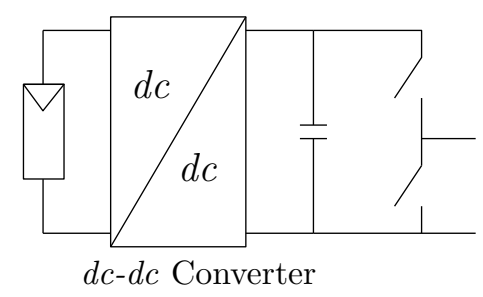

(c)

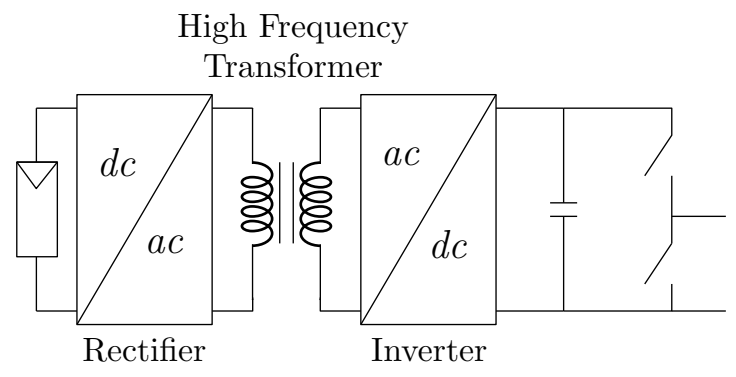

(d)

Figure 1. The Modular Multilevel Converter (MMC) and sub-modules with photovoltaic (PV) panels. (a) Three-phase MMC indicating the upper and lower arms and the sub-module, (b) the HB sub-module with direct connection of the PV panel, (c) the PV is connected to the sub-module using a non-isolated $d c-d c$ converter, and (d) the PV is connected to the sub-module using a isolated converter. 


\section{Direct Connection of PV Panels to the MMC}

To utilize the modularity, increase efficiency, and reliability of the MMC, either a group or individual PV panels is connected directly to the sub-modules of the MMC. Such a configuration inherits the advantages of the MMC such as redundancy, fault-tolerant operation, improved harmonic performance, and hot-swap.

The topology of the MMC with the direct connection of PV panels to the sub-module is shown in Figure 2. Two PV panels are connected in series to form a string which is connected to the sub-module with a series diode to avoid power flow into the PV string. The number of PV panels connected in series or parallel depends on the sizing of the PV plant. Such a configuration is versatile and can have " $6 N$ " independent MPPT algorithms. The MPPT granularity is defined as the number of independent MPPT. The MMC can be controlled such that MPPT is performed either at sub-module, arm, or MMC level depending on the irradiance pattern. This will ensure high energy yield under different operating conditions.

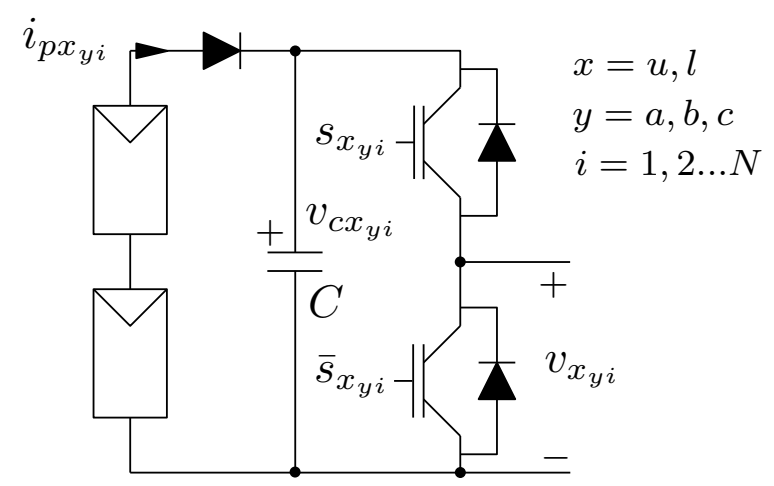

Figure 2. The PV string, two PV panels in series, is connected to the $i$ th sub-module. A diode is included to avoid the power flow into PV string.

The sub-module is said to be inserted when the capacitor is included in the arm of the MMC, i.e., when insertion index $n_{x_{y i}}=1$. When the capacitor is not included in the arm of the MMC, the corresponding sub-module is said to be bypassed, i.e, when insertion index is $n_{x_{y i}}=0$. When the sub-module is inserted the output voltage of the sub-module is $v_{x_{y i}}=n_{x_{y i}} \cdot v_{c x_{y i}}$. Therefore, the voltage across the arm of the MMC is sum of the individual sub-module output voltages expressed as

$$
v_{x}=\sum_{i=1}^{N} n_{x_{y i}} \cdot v_{c x_{y i}}
$$

The current through the sub-module capacitor voltage is expressed as

$$
C \frac{d}{d t}\left(v_{c x_{y i}}\right)=i_{p x_{y i}}+n_{x_{y i}} \cdot i_{x_{y}}
$$

The current from the PV string, $i_{p x_{y i}}$, depends on the irradiance level, temperature, and the capacitor sub-module voltage. To track the maximum power on each sub-module, the capacitor voltage is varied and retained at an operating point where the maximum power is extracted from the PV string. When the sub-module is inserted the magnitude of the capacitor voltage changes based on the net current through the capacitor. In this configuration, the PV string current always has a positive average value, however, the arm current alternates sinusoidally. Therefore, the sub-modules in the arm of the MMC have to be selectively inserted or bypassed to reduce the error between the capacitor voltage and the Maximum Power Point (MPP) voltage.

The fundamental sub-module capacitor ripple voltage also influences the power extracted from the PV string. In [20], the effective power loss per panel is studied concerning the sub-module capacitor 
voltage ripple. For a fixed switching frequency, irradiance of $1000 \mathrm{~W} / \mathrm{m}^{2}$, and at a constant temperature, it is shown that the decrease of sub-module capacitor voltage ripple from $10 \%$ to $5 \%$ results in a decrease of effective loss of power extracted from PV panel, i.e., from $2.47 \%$ to $0.56 \%$, respectively.

In Figure 3a, the voltage across the sub-module capacitor is shown for capacitance between $20 \mathrm{mF}$ to $100 \mathrm{mF}$ incremented in steps of $10 \mathrm{mF}$. The data from the Canadian Solar CS6K-285M-FG PV panel is used for the analysis. The maximum allowed sub-module capacitor voltage is $75 \mathrm{~V}$. The switching frequency is selected to be $10 \mathrm{kHz}$, the irradiance is maintained at $1000 \mathrm{~W} / \mathrm{m}^{2}$. Figure 3 shows the capacitance of the sub-module against the capacitor voltage ripple, to keep the fundamental ripple voltage within $5 \%$ of the rated sub-module capacitor voltage the capacitance has to be greater than $50 \mathrm{mF}$. This capacitance is easily attainable as the sub-module operates at low voltage in the order of few tens of volts.

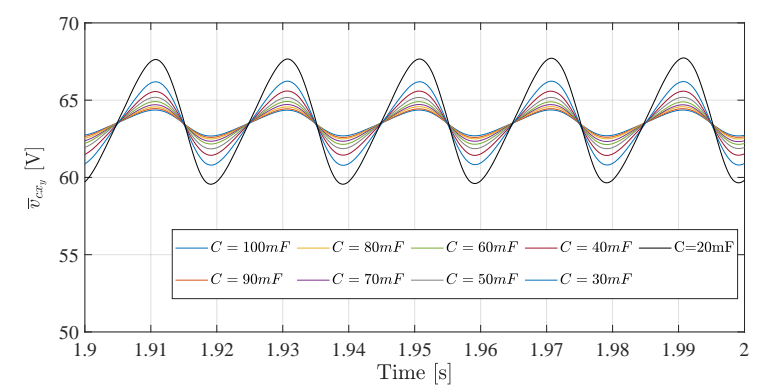

(a)

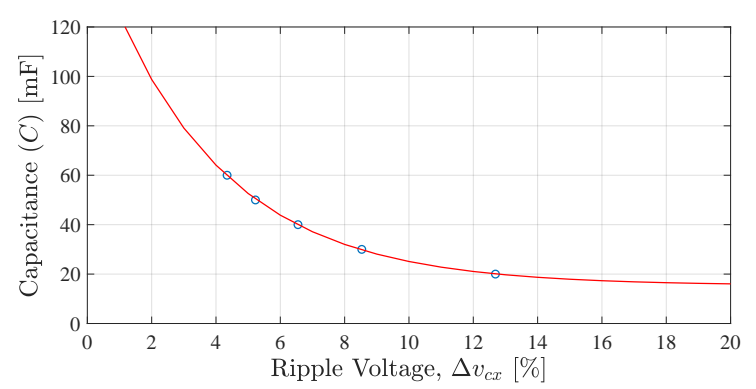

(b)

Figure 3. (a) Sub-module capacitor voltages for different value of capacitance ranging from $20 \mathrm{mF}$ to $100 \mathrm{mF}$ in steps of $10 \mathrm{mF}$. (b) Sub-module capacitance as a function of ripple voltage at maximum rated capacity of the plant operating with $10 \mathrm{kHz}$ switching frequency.

\section{Arm Power Control of MMC Based PV Plant}

The block diagram of arm power control proposed in [13] is shown in Figure 4. The power in each arm of the MMC is independently controlled such that (1) each phase of the MMC delivers the same balanced power to the grid, and the (2) maximum power from the PV is extracted in each arm of the MMC. Such a control method leads to MPPT granularity of six.

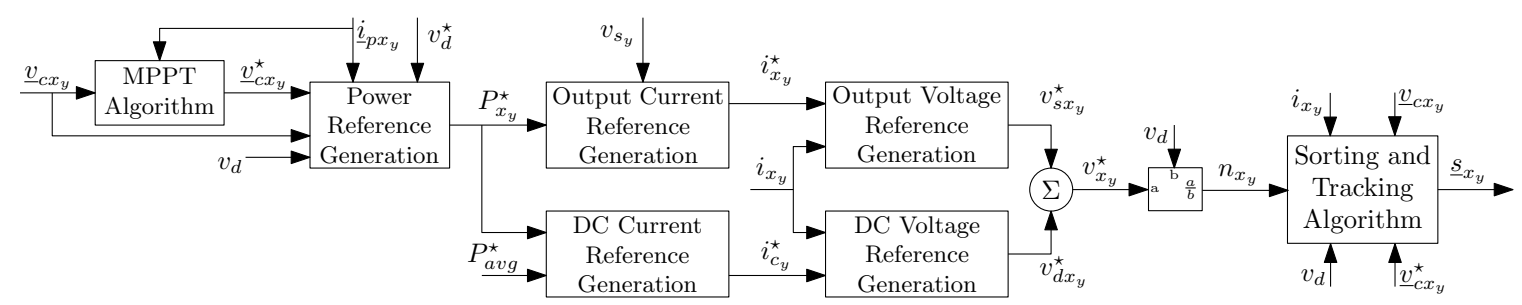

Figure 4. The block diagram of arm power control method of the MMC for PV application proposed in [13].

The MPPT Algorithm provides the individual voltage references for the sub-modules in arm of the MMC as a vector, $\underline{v}_{c x_{y}}^{\star}[1 \times \mathrm{N}]$. These voltage references are added to obtain the desired sum-capacitor voltage reference for individual arm of the MMC, i.e., $v_{c x_{y}}^{\sum \star}=\sum_{i=1}^{N} v_{c x_{y i}}^{\star}$. A Proportional-Integral (PI) controller is used to generate the power reference such that the voltage error between $v_{c x_{y}}^{\Sigma \star}$ and $v_{d c}$ is driven to zero as

$$
P_{x_{y}}^{\star}(s)=\left[v_{c x_{y}}^{\Sigma \star}(s)-v_{d c}(s)\right] \cdot\left(k_{p_{d c}}+\frac{k_{i_{d c}}}{s}\right)
$$

The ac current reference for the arm of the MMC is calculated using the power reference $\left(P_{x_{y}}^{\star}\right)$ and the grid voltage at the point of common coupling. The $d c$ current reference for the arm of the MMC is obtained with a PI controller to drive the error between the arm power reference and the average arm 
power to zero. The average arm power is the mean of power extracted from the PV in each arm of the MMC, defined as in (4).

$$
P_{\text {avg }}=\frac{1}{6}\left(\sum_{y=a, b, c}\left[\sum_{x=u, l}\left\{\sum_{i=1}^{N} v_{c x_{y i}} \cdot i_{p x_{y i}}\right\}\right]\right)
$$

The desired voltage reference for each arm of the MMC is obtained as sum of outputs from "output voltage reference generation" and the " $d c$ voltage reference generation" blocks, respectively. In the $d c$ voltage reference generation, a separate Proportional Resonant (PR) controller is used to suppress the second harmonic circulating current. The insertion index for the arm is calculated as (5) using the arm voltage reference, $v_{x_{y}}^{\star}$.

$$
n_{x_{y}}=\frac{v_{x_{y}}^{\star}}{v_{d c}}=\frac{\sum_{i=1}^{N} n_{x_{y i}} \cdot v_{c x_{y i}}}{v_{d c}}
$$

The number of sub-module inserted in a switching period is positive integer value of $N_{x_{y}}$, i.e., $N_{x_{y}}=\left[n_{x_{y}} \cdot N\right]$. The "Sorting and Tracking Algorithm" is shown in Figure 5, the sub-modules are referred as SM in the algorithm. It enables the insertion and bypass of the sub-module in a switching period such that the sub-module voltages in an arm of the MMC are maintained to their desired values. However, in [13], all the sub-module capacitor voltages in an arm of the MMC are maintained equal. The scenario of the uneven irradiance within the arm of the MMC has not been considered. Such an uneven irradiance within the arm of the MMC will result in different sub-module capacitor voltage references from the MPPT algorithm. The algorithm provides the provision to address unequal irradiance between the sub-modules in an arm of the MMC. The list $L_{1}$ contains all the sub-modules with voltage less than their MPPT references, and $L_{2}$ contains all the sub-modules with voltage greater than their MPPT references. Based on the polarity of the arm current and the magnitude of the sub-module capacitor voltages, the sub-modules are either inserted or bypassed to maintain the voltage within a threshold $\epsilon$. The only limitation is that all the sub-module capacitor voltage references are identical for an arm of the MMC, i.e., $\forall i=1$ to $N, v_{c x_{y i}}=v_{c x}^{\star}$.

For this study, the parameters of the MMC are identical to the case considered in [13], as tabulated in Table A1. The PI- and PR-controller parameters are shown in Table A2.

\section{Scenario 1}

In this scenario, all the PV panels connected to the sub-module of the MMC receive equal irradiance. At the Standard Test Condition (STC), the irradiance is $1000 \mathrm{~W} / \mathrm{m}^{2}$, cell temperature is 25 ${ }^{\circ} \mathrm{C}$, and airmass is 1.5. The operation of the MMC under STC, where all the sub-module receive equal irradiance of $1000 \mathrm{~W} / \mathrm{m}^{2}$ is shown in Appendix B.

All the sub-module capacitor voltages $\left(v_{c x_{y}}[V]\right.$ for $\mathrm{x}=\mathrm{u}, 1$ and $\mathrm{y}=\mathrm{a}, \mathrm{b}, \mathrm{c}$, respectively) are maintained at the desired MPP voltage references, as shown in Appendix B Figure A1a. Active power $(P[k W])$ is injected to the grid by maintaining zero reactive power $(Q[K V A r])$. During the entire operation of the MMC the $d c$ and $a c$ circulating currents are zero, as shown in Appendix B Figure A1b.

The frequency spectrum of the phase currents injected to the grid for scenario 1 is analyzed in this paper and are shown in Figure 6a-c. The THD for each phases are 1.01\%, 1.1\%, and 1.04\% for phase " $a$ ", " $b$ ", and "c" currents, respectively. The THD of currents in each phase do not vary significantly. The control of the MMC makes sure that the distortion in all the three phases are minimized by maintaining the desired $a c$ voltage reference. The THD is well below the $5 \%$ limit as required by IEEE 519 [21] for the scenario 1. 


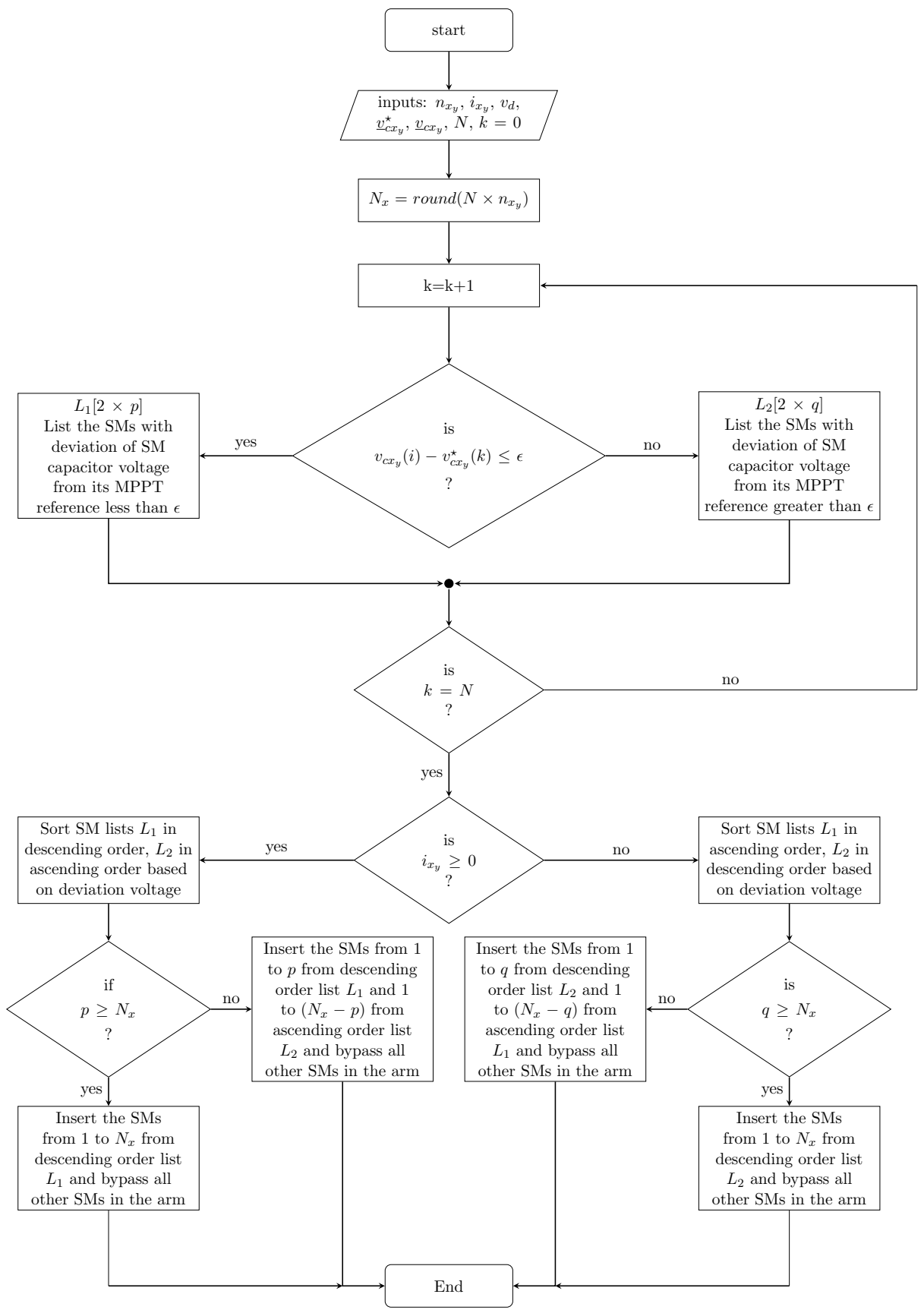

Figure 5. The sorting and tracking algorithm used in the arm power control of the MMC for PV application [13].

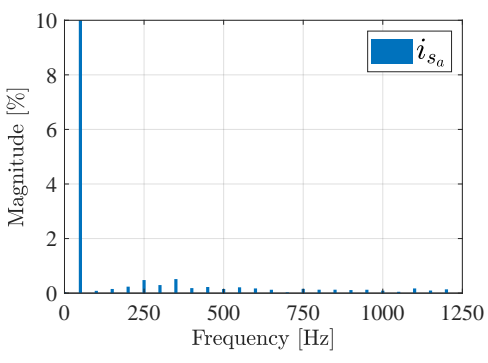

(a) $\mathrm{THD}=1.01 \%$

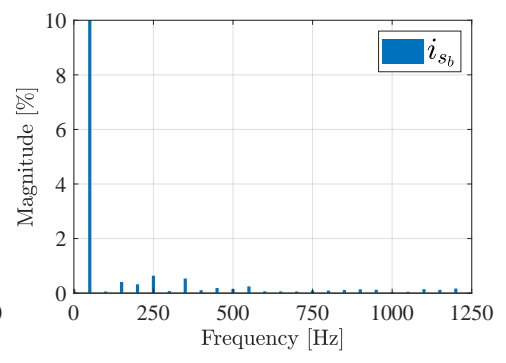

(b) $\mathrm{THD}=1.1 \%$

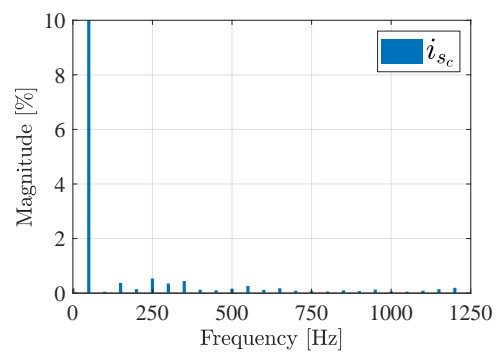

(c) $\mathrm{THD}=1.04 \%$

Figure 6. Frequency spectrum of the output phase currents in \% with respect to the $50 \mathrm{~Hz}$ fundamental current (100\%). 
The positive, negative and zero sequence components of the three phase currents are shown in Figure 7. The negative sequence component under steady state is less that $1 \mathrm{~A}$. The amount of unbalance in the currents is $0.3 \%$ for scenario 1 .
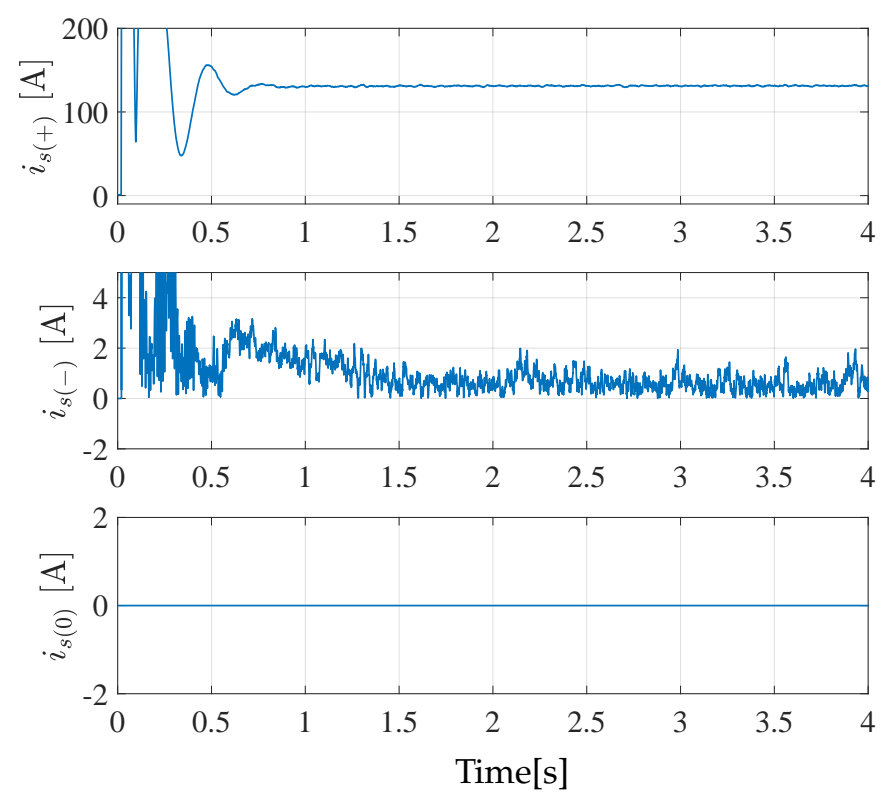

Figure 7. The positive sequence current $\left(i_{s(+)}\right)$, negative sequence current $\left(i_{s(-)}\right)$, and zero sequence current $\left(i_{s(0)}\right)$ for the currents injected to the grid.

\section{Uneven Irradiance and Its Consequence}

The distribution of irradiance pattern within an arm of the MMC is highly dependent on weather conditions and shading. In [13], the irradiance across the sub-modules in an arm of the MMC are assumed to be identical, and the MPPT is allowed only at arm-level. Such a restriction decreased the harvested power when the irradiance is uneven across the sub-modules in an arm of the MMC. Therefore, the sub-module level MPPT is investigated in this section as scenario 2.

\section{Scenario 2}

In this section, a scenario is considered where the irradiance across the PV panels connected to sub-modules in an arm of the MMC is uneven. The sub-modules in an arm of the MMC are allowed to track MPPT by providing individual MPP references from the MPPT algorithm to the power reference generation block in the controller.

If the sub-module capacitor voltage is allowed to follow the MPPT reference within the arm of the $\mathrm{MMC}$, then each sub-module in the arm will deviate from the average value i.e., $v_{c x_{y i}} \neq v_{c x_{y}}^{\Sigma} / N$.

The current controllers will increase or decrease the inserted arm voltage reference to compensate for the voltage difference due to unequal sub-module voltages in the arm of the MMC. However, the sorting and tracking algorithm does not account for the voltage error between the desired arm voltage and the arm voltage to be inserted. This voltage error varies based on choice of sub-modules to be inserted. This leads to a voltage error in each switching period per arm of the MMC, resulting in a residual voltage. This residual voltage per phase (sub-script ' $y$ ' is dropped for simplicity) can be expressed as

$$
v_{x, \epsilon}=N\left(\frac{v_{x}^{\star}}{v_{d c}}\right)-\sum_{j=1}^{N_{x}} v_{c x_{K(j)}}
$$

where the ' $K$ ' is a row matrix $\left[1 \times N_{x_{y}}\right]$ with the sub-module indexes to be inserted. Therefore, $v_{c x_{y K(j)}}$ will yield the value of the sub-module capacitor whose index is stored in the $j$ th location of the row matrix ' $K$ '. 
If the residual error is large then it will lead to increased harmonics in the output current. Such a variation is acceptable until the THD is well below 5\% as required by IEEE 519 [21] and that no $d c$ current greater than $0.5 \%$ of the rated current is injected to the grid [22].

The simulation results are shown where the irradiance is linearly distributed across all of the upper and lower arms of the MMC from $10 \mathrm{~W} / \mathrm{m}^{2}$ to $1000 \mathrm{~W} / \mathrm{m}^{2}$. For the scenario considered, the sub-module capacitor voltages are shown in Figure $8 \mathrm{a}$ for each of the six arms of the MMC. Figure $8 \mathrm{~b}$ shows the upper and lower arm currents $\left(i_{u_{y}}[A], i_{l_{y}}[A]\right)$, output currents $\left(i_{s_{y}}[A]\right)$, circulating currents $\left(i_{c_{y}}[A] \forall \mathrm{y}=\mathrm{a}, \mathrm{b}, \mathrm{c}\right)$, the active and reactive power injected to the grid $(P[k W], Q[k V A r])$, and the last plot shown the voltages $\left(v_{s_{y}}[V] \forall \mathrm{y}=\mathrm{a}, \mathrm{b}, \mathrm{c}\right)$ at PCC along with the phase currents $\left(i_{s_{y}}[A]\right)$ for $100 \mathrm{~ms}$ duration between $4.9 \mathrm{~s}$ to $5 \mathrm{~s}, \forall \mathrm{y}=\mathrm{a}, \mathrm{b}, \mathrm{c}$.
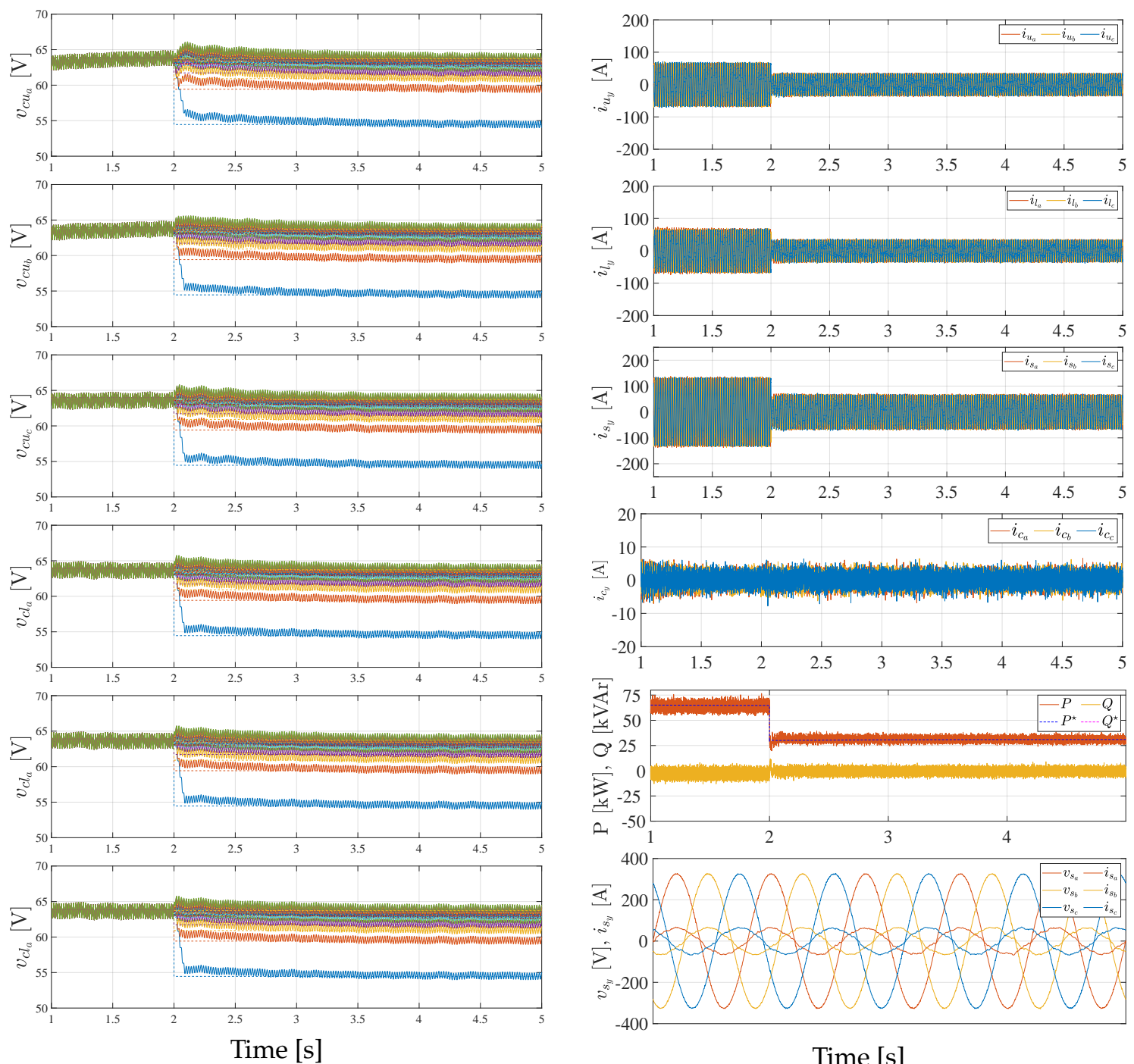

(a)

(b)

Figure 8. Simulation results for scenario 2: (a) Capacitor voltages for all the sub-modules in an arm of the MMC for all three phases. From the top, upper arm phase "a", upper arm phase " $b$ ", upper arm phase "c", lower arm phase "a", lower arm phase " $b$ ", and lower arm phase "c", respectively. (b) The upper and lower arm currents $\left(i_{u_{y}}[A], i_{l_{y}}[A]\right)$, output currents $\left(i_{s_{y}}[A]\right)$, circulating currents $\left(i_{\mathcal{c}_{y}}[A] \forall \mathrm{y}=\mathrm{a}, \mathrm{b}, \mathrm{c}\right)$, the active and reactive power injected to the grid (P[kW], $\left.Q[k V A r]\right)$, and the plot shown the voltages $\left(v_{s_{y}}[V] \forall \mathrm{y}=\mathrm{a}, \mathrm{b}, \mathrm{c}\right)$ at PCC and the phase currents $\left(i_{s_{y}}[A]\right)$ for 100 ms duration between $4.9 \mathrm{~s}$ to $5 \mathrm{~s}, \forall \mathrm{y}=\mathrm{a}, \mathrm{b}, \mathrm{c}$. 
It is seen that the sorting and tracking algorithm [13] can be used for tracking the MPP voltages for the respective sub-modules by providing the individual references from the MPPT algorithm instead of a average voltage. Moreover, balanced active power is injected to the grid at unity power factor. Since each arm of the MMC produces equal power there is no need to transfer power between the phases of the MMC. Hence the circulating current is zero. The Figure 9 shows the residual voltage defined as in (6). The Figure 10a-c shows the frequency spectrum of the phase currents; the THDs are $5.11 \%, 5.28 \%$, and $5.36 \%$ for phase $a, b$, and c currents, respectively. It is seen that the THD is higher that the permitted level as per IEEE 519 standard.

The positive, negative, and zero sequence components of the three-phase currents are shown in Figure 11 for the scenario 2. It is seen that the unbalance current injected to the grid is well within $0.5 \%$ of the rated magnitude of phase current for the scenario 2.

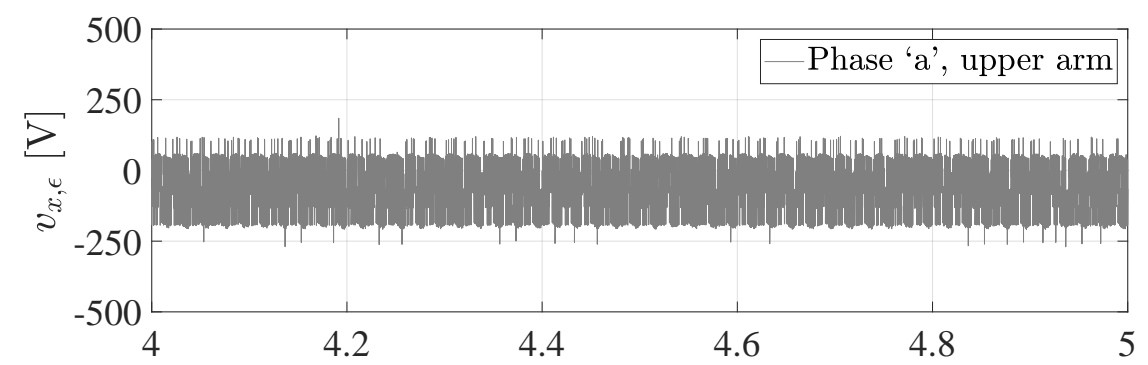

Figure 9. The residual voltage as defined in (6) for the phase a upper arm of the MMC.

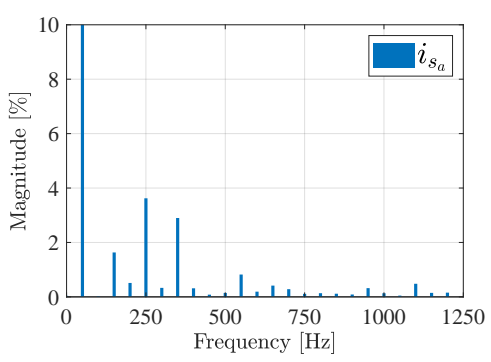

(a) $\mathrm{THD}=5.11 \%,\left\|i_{s_{1}}\right\|=43.06 \mathrm{~A}$

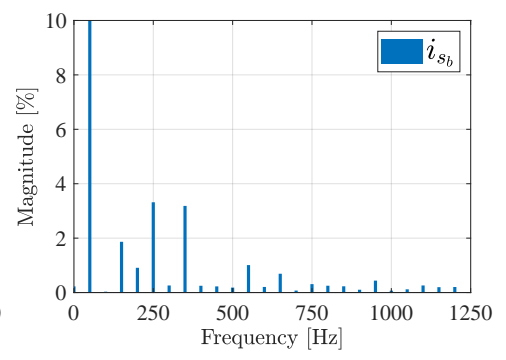

(b) $\mathrm{THD}=5.11 \%,\left\|i_{s_{b_{1}}}\right\|=43.11 \mathrm{~A}$

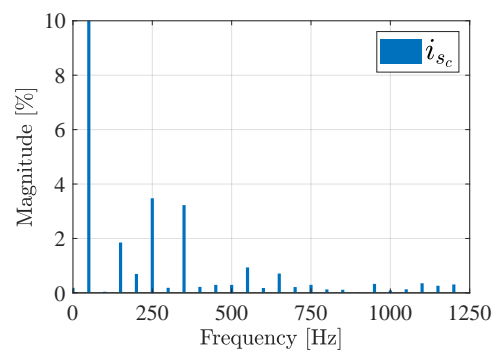

(c) $\mathrm{THD}=5.11 \%,\left\|i_{s_{c_{1}}}\right\|=43.06 \mathrm{~A}$

Figure 10. Frequency spectrum of the output phase currents in \% with respect to the $50 \mathrm{~Hz}$ fundamental current, $\left\|i_{s_{y_{1}}}\right\| \forall \mathrm{y}=\mathrm{a}, \mathrm{b}, \mathrm{c}$.
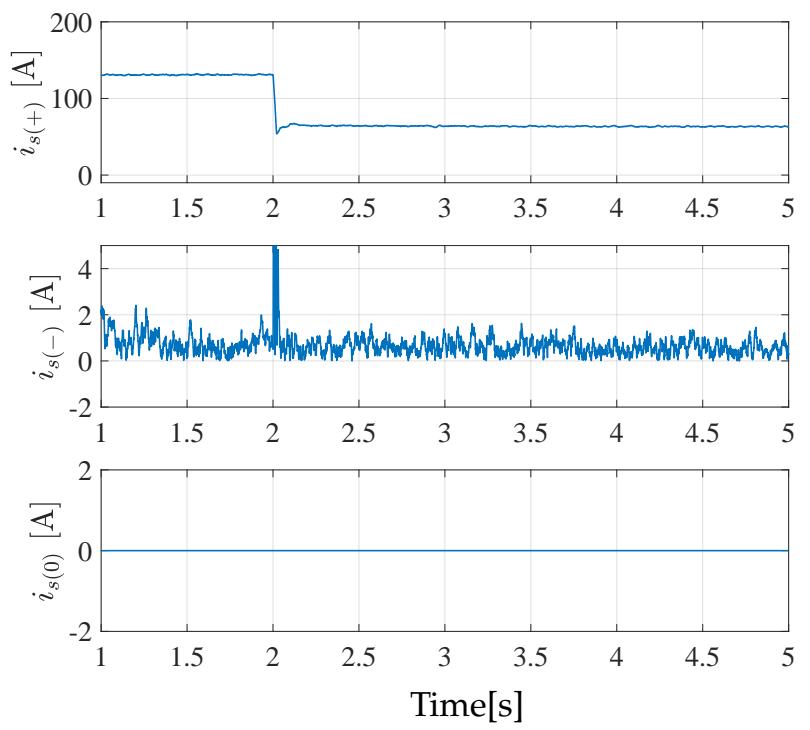

Figure 11. The positive sequence current $\left(i_{s(+)}\right)$, negative sequence current $\left(i_{s(-)}\right)$, and zero sequence current $\left(i_{s(0)}\right)$ for the currents injected to the grid for scenario 2. 


\section{Modified Sorting and Tracking Algorithm}

The sorting and tracking algorithm enables the MMC to have individual MPPT for each sub-module, as seen in scenario 2. This increases the MPPT granularity of the MMC-based PV plant to $6 \mathrm{~N}$. For the plant considered in this paper, the MPPT granularity will be 114. The drawback is that the residual error leads to harmonic distortion at the output current. Based on the operating condition, the value of the harmonic distortion might not adhere to the value permitted by the IEEE standard 519 [21]. Therefore, to ensure that for all operating steady-state conditions the harmonic distortion is within the limits, the residual voltage has to be alleviated. The voltage error as per (6) has to be mitigated to reduces the harmonic distortion and any unbalance in current injected to the grid.

In this section, a modified sorting and tracking algorithm is proposed that takes into account the voltage error and increases or decreases the insertion indexes. Further, during a switching period one of the inserted sub-modules is pulse-width modulated such that the average value of the inserted arm voltage inserted matches the desired arm voltage in a switching period. Sub-modules with minimum or maximum voltage deviation from their MPP voltage value are selected, based on the arm current polarity, for PWM in every switching period. Therefore, the duty ratio and the sub-module index for the PWM changes every switching period. By doing so, the loss of power extraction from the PV panel due to the PWM of the sub-module is minimized.

The sorting and tracking algorithm selects the $N_{x}$ sub-modules to be inserted per arm of the MMC in a given phase, with this the residual voltage is computed as per (6). If the error is negative, then the insertion index is increased to minimize the error. If the error is positive, then the insertion index is decreased to mitigate the residual voltage. The insertion index is either increased or decreased until the magnitude of the ratio as per (7) is less than one, this will be the modified number of sub-modules to be inserted " $N_{x}^{\star \prime}$.

$$
w=\frac{\left|v_{x, \epsilon}\right|}{\sum_{j=1}^{N_{x}} v_{\mathcal{C x}}}
$$

If the arm current is positive (or negative) then the sub-module with the lowest (or highest) voltage in the set of sub-modules to be inserted is selected for modulation. The duty ratio is the calculated as

$$
d=\frac{\left|N\left(\frac{v_{x}^{\star}}{v_{d c}}\right)-\sum_{j=1}^{N_{x}^{\star}} v_{c x_{K(j)}}\right|}{\sum_{j=1}^{N_{x}^{\star}} v_{c x_{K(j)}}}<1
$$

\section{Scenario 3}

This scenario is identical to scenario 2; however, the modified sorting and tracking algorithm is used to mitigate the THD which is observed in scenario 2 . The index of the sub-module to be modulated and the duty ratio " $d$ " is shown in Figure 12 for $10 \mathrm{~ms}$ duration. The index and the duty ratio is modified every switching period so that the average value of the arm voltage is equal to the desired arm voltage.

Figure 13 shows the residual voltage as a result of using modified sorting and a tracking algorithm. The average value of the residual voltage is now zero, and the instantaneous magnitude of the residual voltage over a switching period is lower than the value seen in scenario 2 . 

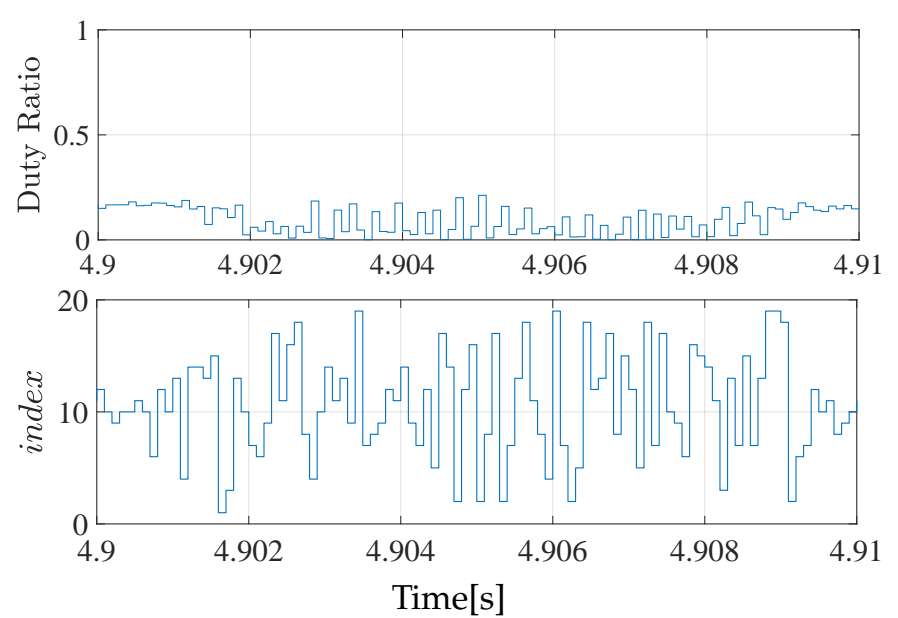

Figure 12. The duty ratio for Pulse Width Modulators (PWM) and the index of the sub-module to be modulated.

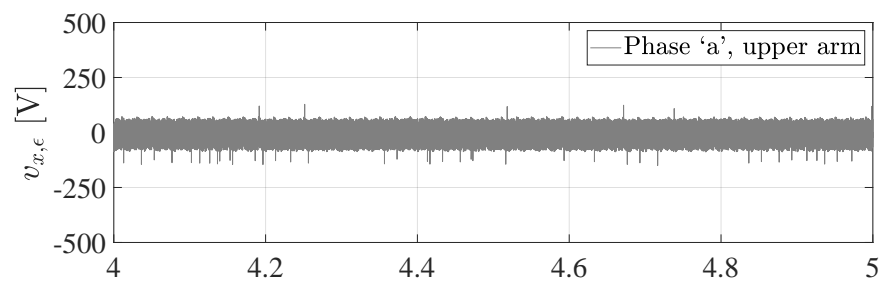

Figure 13. The residual voltage as defined in (6) for the phase "a" upper arm of the MMC with modified ST algorithm.

The frequency spectrum of the output phase currents is shown in Figure 14. the THD is calculated to be $3.68 \%, 3.75 \%$, and $3.56 \%$ for phase a, b, and c currents, respectively. The THD is decreased by $30 \%$ bringing it well within the permitted level as per IEEE 519 standard.

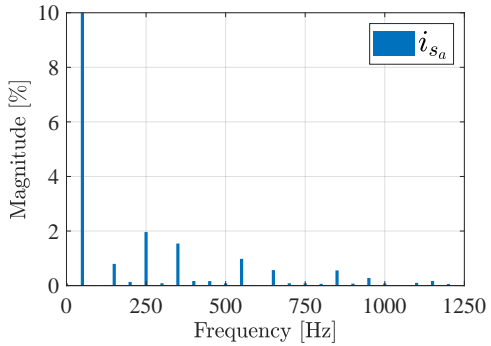

(a) $\mathrm{THD}=3.68 \%,\left\|i_{s_{1}}\right\|=44.71 \mathrm{~A}$

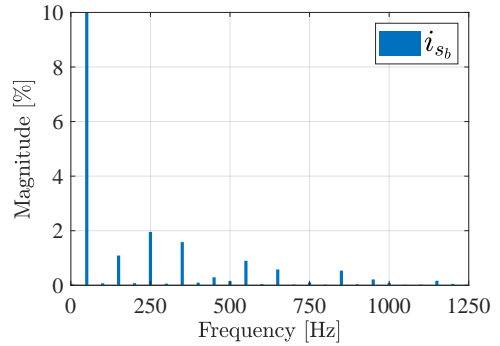

(b) $\mathrm{THD}=3.75 \%,\left\|i_{s_{b_{1}}}\right\|=44.88 \mathrm{~A}$

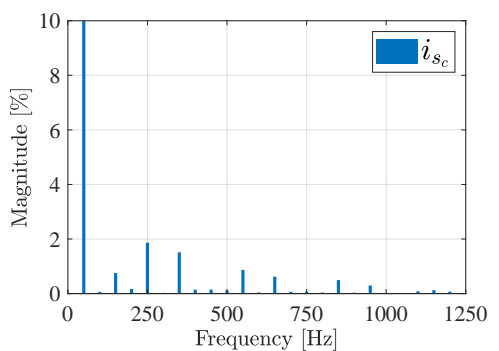

(c) $\mathrm{THD}=3.56 \%,\left\|i_{s_{c_{1}}}\right\|=44.74 \mathrm{~A}$

Figure 14. Frequency spectrum of the output phase currents in \% with respect to the $50 \mathrm{~Hz}$ fundamental current, $\left\|i_{s_{y_{1}}}\right\| \forall \mathrm{y}=\mathrm{a}, \mathrm{b}, \mathrm{c}$.

\section{Conclusions}

The simulation results of the MMC-based PV plant with arm power control are presented specifically when the irradiance is uneven within the arms of the MMC. The consequence of uneven irradiance on each sub-modules of the arm of the MMC is discussed in terms of harmonic distortion and unbalance in the phase currents. It is seen that the MMC-based PV plant is capable of tracking the maximum power at individual sub-module level brining the MPPT granularity to " $6 \cdot \mathrm{N}$ ". This is achieved without any additional $d c-d c$ converters.

It is further noticed that, based on the operating conditions, the harmonic distortion in the output currents increases due to residual voltage between the actual inserted arm voltage and the desired arm voltage. The effect of this residual voltage is the increase in THD and the amount of unbalance 
in the output current. Though there is no strict requirement on the unbalance, usually a balanced operation is desired for stable operating conditions. Furthermore, there is a strict requirement on the THD of the currents injected into the $a c$ grid. It is seen that based on the operating load and irradiance pattern on the PV panels connected to the MMC the THD values can be higher than $5 \%$, which is the allowed limit.

In this paper a modified sorting and tracking algorithm is proposed to the arm power control of the MMC. It enables the effective operation of the MMC-based PV plant even under unequal irradiance patterns across the sub-modules. For the case considered, it is shown that the THD is reduced by $30 \%$, bringing it well within the permitted limit.

Author Contributions: Conceptualization, methodology, and validation: A.B.A., formal analysis: R.T. and D.S. Article is written by A.B.A. Article is reviewed by R.T., L.E.N., and D.S. All authors have read and agreed to the published version of the manuscript.

Funding: This project has received funding from the European Union's Horizon 2020 research and innovation programme under the Marie Skłodowska-Curie grant agreement No 845122.

Conflicts of Interest: The authors declare no conflicts of interest

\section{Nomenclature}

$x=u$ or $l$
$y=a, b$ or $c$
$i=1,2,3 \ldots$
$N$
$n_{x_{y_{i}}}$
$n_{x_{y}}$
$i_{x_{y}}$
$i_{s_{y}}$
$i_{c_{y}}$
$i_{p x_{y i}}$
$v_{c x_{y i}}$
$v_{c x_{y}}$
$v_{x_{y}}$
$v_{S_{y}}$
$v_{c x_{y}}$
$v_{d c}$
$P$
$Q$

Upper $(u)$ or Lower $(l)$ arm

Phase $a, b$ or $c$

Sub-Module index

Number of Sub-Modules

Insertion index of $i$ th Sub-Module in upper or lower arm per phase

Insertion index of upper or lower arm per phase

Upper or lower arm current per phase

Output current per phase

Circulating current per phase

PV string current in $i$ th Sub-Module per phase

Capacitor voltage of $i$ th Sub-Module in upper or lower arm per phase

Sum capacitor voltage of upper or lower arm per phase

Inserted upper or lower arm voltage per phase

Output voltage in each phase

Average arm capacitor voltage per phase

Effective DC link voltage

Three phase active power

Three phase reactive power

\section{Appendix A. Parameters of Modular Multilevel Converter}

Table A1. Parameters of MMC Converters.

\begin{tabular}{ccc}
\hline Parameters & Symbol & Value \\
\hline Rated Apparent Power & $S_{s}$ & $65 \mathrm{kVA}$ \\
Rated Output Voltage & $v_{s}$ & $400 \mathrm{~V}$ \\
Rated Output Current & $i_{s}$ & $141 \mathrm{~A}$ \\
Output Frequency & $f_{s}$ & $50 \mathrm{~Hz}$ \\
Maximum DC Voltage & $v_{d c}$ & $1.4 \mathrm{kV}$ \\
SM Capacitance & $C$ & $20 \mathrm{mF}$ \\
Arm Inductance & $L_{a}$ & $1.2 \mathrm{mH}$ \\
Rated SM Voltage & $v_{c x}$ & $63.4 \mathrm{~V}$ \\
Maximum SM Voltage & $v_{c x}(\max )$ & $75 \mathrm{~V}$ \\
Switching Frequency & $f_{s w}$ & $10,000 \mathrm{~Hz}$ \\
Number of SMs & $N$ & 19 \\
\hline
\end{tabular}


Table A2. Controller parameter.

\begin{tabular}{cc}
\hline & $k_{p_{d c}}=40 \mathrm{~W} / \mathrm{V}$ \\
Power Reference Generation & $\tau_{i_{d c}}=10 \mathrm{~s}$ \\
& $k_{p_{x}}=100 \mathrm{~W} / \mathrm{V}$ \\
& $\tau_{i_{x}}=333 \mathrm{~ms}$ \\
\hline \multirow{5}{*}{ Output Current Controller } & $k_{p_{\alpha}}=2 \mathrm{~V} / \mathrm{A}$ \\
& $k_{i_{\alpha}}=209 \mathrm{~V} / \mathrm{A}$ \\
& $k_{p_{\beta}}=2 \mathrm{~V} / \mathrm{A}$ \\
& $k_{i_{\beta}}=209 \mathrm{~V} / \mathrm{A}$ \\
\hline Circulating Current Controller & $k_{p_{c}}=0.04 \mathrm{~V} / \mathrm{A}$ \\
& $k_{i_{c}}=400 \mathrm{~V} / \mathrm{A}$ \\
& $k_{p_{d}}=40 \mathrm{~V} / \mathrm{A}$ \\
& $\tau_{i_{d}}=4 \mathrm{~s}$ \\
\hline
\end{tabular}

\section{Appendix B. Simulation Results of MMC Based PV Plant at STC}
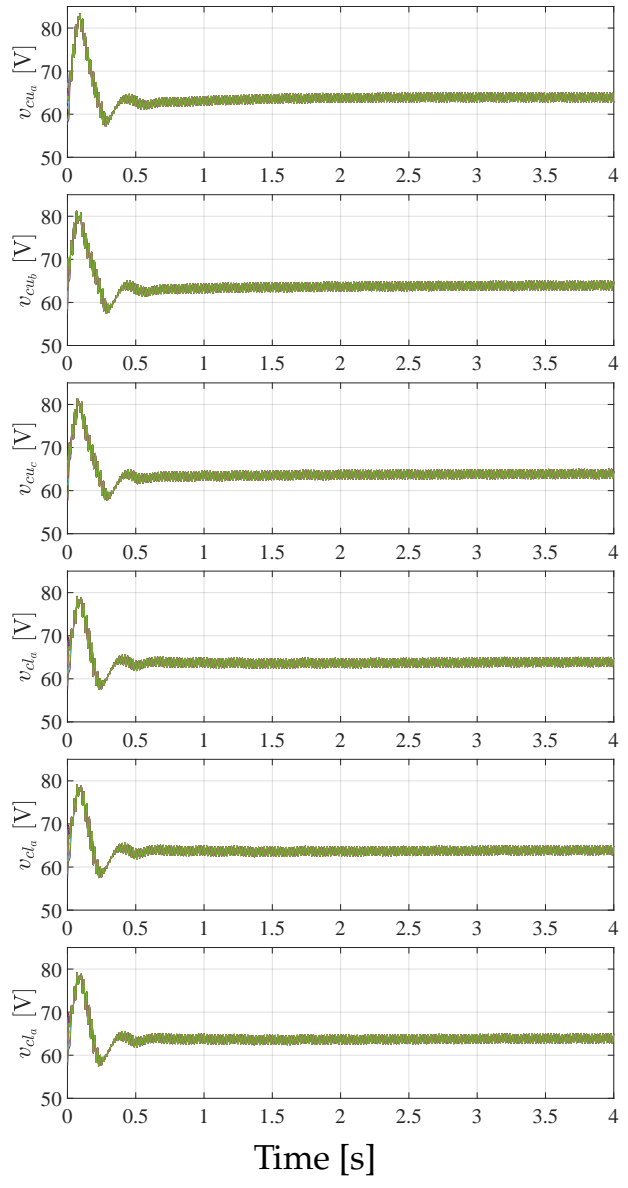

(a)
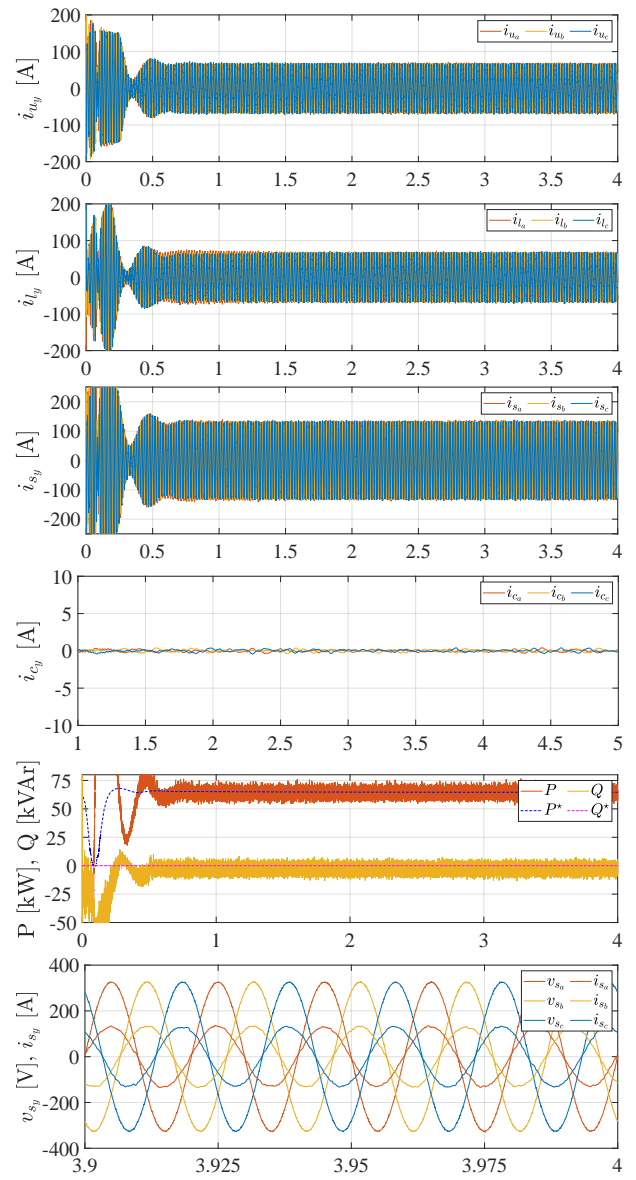

Time [s]

(b)

Figure A1. Simulation results for scenario 1 (a) Capacitor voltages for all the sub-modules in an arm of the MMC for all three phases. From the top, upper arm phase "a", upper arm phase " $b$ ", upper arm phase "c", lower arm phase "a", lower arm phase " $b$ ", and lower arm phase "c", respectively. (b) The upper and lower arm currents $\left(i_{u_{y}}[A], i_{l_{y}}[A]\right)$, output currents $\left(i_{s_{y}}[A]\right)$, circulating currents $\left(i_{c_{y}}[A] \forall \mathrm{y}=\mathrm{a}, \mathrm{b}, \mathrm{c}\right)$, the active and reactive power injected to the grid $(P[k W], Q[k V A r])$ and the plot shown the voltages $\left(v_{s_{y}}[V] \forall \mathrm{y}=\mathrm{a}, \mathrm{b}, \mathrm{c}\right)$ at PCC and the phase currents $\left(i_{s_{y}}[A]\right)$ for 100 ms duration between $4.9 \mathrm{~s}$ to $5 \mathrm{~s}, \forall \mathrm{y}=\mathrm{a}, \mathrm{b}, \mathrm{c}$.

The simulation results under STC is presented. Figure A1 shows the sub-module capacitor voltages in each arm of the MMC. The voltage is retained at their respective MPP voltage at STC. 
Figure A1 shows the arm currents $\left(i_{u_{y}}[A], i_{l_{y}}[A]\right)$, the output phase currents $\left(i_{s_{y}}[A]\right)$, the insertion indexes $\left(n_{u_{y}}\right)$ for the upper arm in all the phases, the active and reactive power $(P[k W], Q[k V A r])$, along with the reference values and the voltages at PCC $\left(v_{s_{y}}[V]\right)$ and output currents $\left(i_{s_{y}}[A]\right)$ for a $100 \mathrm{~ms}$ duration between $3.9 \mathrm{~s}$ to $4 \mathrm{~s}$.

\section{References}

1. Bogdanov, D.; Farfan, J.; Sadovskaia, K.; Aghahosseini, A.; Child, M.; Gulagi, A.; Oyewo, A.S.; de Souza Noel Simas Barbosa, L.; Breyer, C. Radical Transformation Pathway towards Sustainable Electricity via Evolutionary Steps. Nat. Commun. 2019, 10, 1-16. [CrossRef]

2. Carrasco, J.M.; Franquelo, L.G.; Bialasiewicz, J.T.; Galván, E.; Portillo Guisado, R.C.; Prats, M.N.M.; León, J.I.; Moreno-Alfonso, N. Power-Electronic Systems for the Grid Integration of Renewable Energy Sources: A Survey. IEEE Trans. Ind. Electron. 2006, 53, 1002-1016. [CrossRef]

3. Rivera, S.; Wu, B.; Lizana, R.; Kouro, S.; Perez, M.; Rodriguez, J. Modular Multilevel Converter for Large-Scale Multistring Photovoltaic Energy Conversion System. In Proceedings of the 2013 IEEE Energy Conversion Congress and Exposition, Denver, CO, USA, 15-19 September 2013; IEEE: Piscataway, NJ, USA, 2013; pp. 1941-1946. [CrossRef]

4. Zhao, W.; Choi, H.; Konstantinou, G.; Ciobotaru, M.; Agelidis, V.G. Cascaded H-Bridge Multilevel Converter for Large-Scale PV Grid-Integration with Isolated DC-DC Stage. In Proceedings of the 2012 3rd IEEE International Symposium on Power Electronics for Distributed Generation Systems (PEDG), Aalborg, Denmark, 25-28 June 2012; pp. 849-856. [CrossRef]

5. Lesnicar, A.; Marquardt, R. An Innovative Modular Multilevel Converter Topology Suitable for a Wide Power Range. In Proceedings of the 2003 IEEE Bologna Power Tech Conference Proceedings, Bologna, Italy, 23-26 June 2003; Volume 3, p. 6. [CrossRef]

6. Akagi, H. Classification, Terminology, and Application of the Modular Multilevel Cascade Converter (MMCC). In Proceedings of the 2010 International Power Electronics Conference-ECCE ASIA, Jeju, Korea, 29 May-2 June 2011; pp. 508-515. [CrossRef]

7. Dekka, A.; Wu, B.; Fuentes, R.L.; Perez, M.; Zargari, N.R. Evolution of Topologies, Modeling, Control Schemes, and Applications of Modular Multilevel Converters. IEEE J. Emerg. Sel. Top. Power Electron. 2017, 5, 1631-1656. [CrossRef]

8. Hakimi, S.M.; Hajizadeh, A. Integration of Photovoltaic Power Units to Power Distribution System through Modular Multilevel Converter. Energies 2018, 11, 2753. [CrossRef]

9. Nademi, H.; Das, A.; Burgos, R.; Norum, L. A New Circuit Performance of Modular Multilevel Inverter Suitable for Photovoltaic Conversion Plants. IEEE J. Emerg. Sel. Top. Power Electron. 2015, 4, 393-404. [CrossRef]

10. Sharifabadi, K.; Harnefors, L.; Nee, H.P.; Norrga, S.; Teodorescu, R. Design, Control and Application of Modular Multilevel Converters for HVDC Transmission Systems; Wiley-IEEE Press: Hoboken, NJ, USA, 2016.

11. Nami, A.; Liang, J.; Dijkhuizen, F.; Demetriades, G.D. Modular Multilevel Converters for HVDC Applications: Review on Converter Cells and Functionalities. IEEE Trans. Power Electron. 2014, 30, 18-36. [CrossRef]

12. Stringfellow, J.D.; Summers, T.J.; Betz, R.E. Control of the Modular Multilevel Converter as a Photovoltaic Interface under Unbalanced Irradiance Conditions with MPPT of Each PV Array. In Proceedings of the 2016 IEEE 2nd Annual Southern Power Electronics Conference (SPEC), Auckland, New Zealand, 5-8 December 2016; IEEE: Piscataway, NJ, USA, 2016; pp. 1-6. [CrossRef]

13. Acharya, A.B.; Ricco, M.; Sera, D.; Teodorescu, R.; Norum, L.E. Arm Power Control of the Modular Multilevel Converter in Photovoltaic Applications. Energies 2019, 12, 1620. [CrossRef]

14. Peftitsis, D.; Tolstoy, G.; Antonopoulos, A.; Rabkowski, J.; Lim, J.K.; Bakowski, M.; Ängquist, L.; Nee, H.P. High-Power Modular Multilevel Converters With SiC JFETs. IEEE Trans. Power Electron. 2011, 27, 28-36. [CrossRef]

15. Acharya, A.B.; Ricco, M.; Sera, D.; Teoderscu, R.; Norum, L.E. Performance Analysis of Medium-Voltage Grid Integration of PV Plant Using Modular Multilevel Converter. IEEE Trans. Energy Convers. 2019, 34, 1731-1740. [CrossRef]

16. Hagiwara, M.; Akagi, H. Control and Experiment of Pulsewidth-Modulated Modular Multilevel Converters. IEEE Trans. Power Electron. 2009, 24, 1737-1746. [CrossRef] 
17. Yang, S.; Tang, Y.; Wang, P. Distributed Control for a Modular Multilevel Converter. IEEE Trans. Power Electron. 2017, 33, 5578-5591. [CrossRef]

18. Münch, P.; Görges, D.; Izák, M.; Liu, S. Integrated Current Control, Energy Control and Energy Balancing of Modular Multilevel Converters. In Proceedings of the IECON 2010-36th Annual Conference on IEEE Industrial Electronics Society, Glendale, AZ, USA, 7-10 November 2010; pp. 150-155. [CrossRef]

19. Soong, T.; Lehn, P.W. Internal Power Flow of a Modular Multilevel Converter With Distributed Energy Resources. IEEE J. Emerg. Sel. Top. Power Electron. 2014, 2, 1127-1138. [CrossRef]

20. Acharya, A.B.; Norum, L.E.; Sera, D. A Shadow Tolerant Configuration for PV Integration to Grid Using Modular Multilevel Converter. In Proceedings of the 2018 IEEE International Conference on Power Electronics, Drives and Energy Systems (PEDES), Chennai, India, 18-21 December 2018; pp. 1-6. [CrossRef]

21. IEEE. IEEE Recommended Practice and Requirements for Harmonic Control in Electric Power Systems; IEEE: New York, NY, USA, 2014; pp. 1-29. [CrossRef]

22. IEEE. IEEE Standard for Interconnection and Interoperability of Distributed Energy Resources with Associated Electric Power Systems Interfaces; IEEE: New York, NY, USA, 2018; pp. 1-138. [CrossRef]

(C) 2020 by the authors. Licensee MDPI, Basel, Switzerland. This article is an open access article distributed under the terms and conditions of the Creative Commons Attribution (CC BY) license (http://creativecommons.org/licenses/by/4.0/). 